\title{
Freckle Defect Formation near the Casting Interfaces of Directionally Solidified Superalloys
}

\author{
Jianping Hong ${ }^{1,2, *}$, Dexin Ma ${ }^{2}$, Jun Wang ${ }^{1,3, *}$, Fu Wang ${ }^{2}$, Baode Sun ${ }^{1,3}$, Anping Dong ${ }^{1}$, \\ Fei $\mathrm{Li}^{1}$ and Andreas Bührig-Polaczek ${ }^{2}$ \\ 1 Shanghai Key Lab of Advanced High-Temperature Materials and Precision Forming, \\ Shanghai Jiao Tong University, Shanghai 200240, China; bdsun@sjtu.edu.cn (B.S.); \\ apdong@sjtu.edu.cn (A.D.); lifei74@sjtu.edu.cn (F.L.) \\ 2 Foundry Institute, RWTH Aachen University, Aachen 52056, Germany; d.ma@gi.rwth-aachen.de (D.M.); \\ f.wang@gi.rwth-aachen.de (F.W.); sekretariat@gi.rwth-aachen.de (A.B.-P.) \\ 3 State Key Laboratory of Metal Matrix Composites, Shanghai Jiao Tong University, Shanghai 200240, China \\ * Correspondence: jianping.hong@hotmail.com (J.H.); junwang@sjtu.edu.cn (J.W.); \\ Tel.: +86-21-5474-2962 (J.H.); +86-21-5474-5387 (J.W.)
}

Academic Editor: Mark T. Whittaker

Received: 31 August 2016; Accepted: 9 November 2016; Published: 16 November 2016

\begin{abstract}
Freckle defects usually appear on the surface of castings and industrial ingots during the directional solidification process and most of them are located near the interface between the shell mold and superalloys. Ceramic cores create more interfaces in the directionally solidified (DS) and single crystal (SX) hollow turbine blades. In order to investigate the location of freckle occurrence in superalloys, superalloy CM247 LC was directionally solidified in an industrial-sized Bridgman furnace. Instead of ceramic cores, Alumina tubes were used inside of the casting specimens. It was found that freckles occur not only on the casting external surfaces, but also appear near the internal interfaces between the ceramic core and superalloys. Meanwhile, the size, initial position, and area of freckle were investigated in various diameters of the specimens. The initial position of the freckle chain reduces when the diameter of the rods increase. Freckle area follows a linear relationship in various diameters and the average freckle fraction is $1.1 \%$ of cross sectional area of casting specimens. The flow of liquid metal near the interfaces was stronger than that in the interdendritic region in the mushy zone, and explained why freckle tends to occur on the outer or inner surfaces of castings. This new phenomenon suggests that freckles are more likely to occur on the outer or inner surfaces of the hollow turbine blades.
\end{abstract}

Keywords: freckles; convection resistance; interface; directional solidification

\section{Introduction}

Superalloys offer excellent high temperature tensile strength, stress rupture and creep properties, fatigue strength, oxidation and corrosion resistance, and micro-structural stability at elevated temperatures $600{ }^{\circ} \mathrm{C}$ or above [1-6]. Nickel-based superalloys are the most complex and the most widely used in high temperature applications. However, because of the factors of alloy chemistry, casting conditions including solidification parameters, and casting geometry, freckles, hot cracking, low angle grain boundaries, and other solidification defects were found in directional solidified (DS) and single crystal (SX) superalloy castings. These solidification defects have a negative influence on high temperature mechanical properties, and reduce the life of aero engine and gas turbine land-based power generation [7-9].

Freckles are macroscopic channel segregation defects which usually appear as a long trail of equiaxed grains with a composition shift consistent with alloy segregation in a wide variety of 
industrial castings, such as vacuum arc remelting (VAR) and electro-slag remelting (ESR) superalloy billets, nickel-based superalloys, or specialty steel, that occur during solidification. They are presently one of the main defects encountered in the advanced casting technology of superalloys [10]. Macro-segregation such as freckles cannot be removed by post-processing, thermo-mechanical treatments, or plastic processing [11,12]. Since the 1960s, when they were linked to the failure of several military engines, freckles are considered to be unacceptable defects in industrial aerospace castings. Freckle defects are highly undesirable in critical applications because of their deleterious effect on mechanical performance and because they cause considerable economic loss.

It is generally agreed that freckles are the product of specific fluid flow patterns, known as thermosolutal convection, originating in the interdendritic liquid during solidification. This flow is driven by a density inversion occurring in the mushy zone as a result of interdendritic segregation. In a previous study, freckle occurrence was found to be dependent on three factors: alloy chemistry, casting conditions, and casting size [10]. Much research has been focused on alloy chemistry and solidification conditions. However, previous empirical knowledge and empirically determined casting parameters seem to be of little help in finding the new appropriate solidification conditions. The local thermal gradient (G), local solidification rate (R), and local solidification time (LST) have already been investigated. Currently, the general acceptant and most complete predictive criteria is the Rayleigh criterion, which combines two of the three factors influencing freckle formation, alloy chemistry and casting conditions, but not casting geometry. Since freckling results from the breakdown of a metastable equilibrium state (heavier liquid atop a lighter one), it is assumed that freckle initiation will always produce fully grown freckles.

In the present study, a variety of single crystal superalloy castings with various geometries such as specimens with multi-interfacial features were created in an industrial Bridgman furnace with a lower withdrawal rate, which is prone to freckle formation. The main goal of this research is freckle formation on the external surface of rods with a variety of diameters (cross sectional area) and freckle formation on both the external and internal surfaces of castings with multi-interfaces. Morphology and composition analysis were investigated with freckle and freckle free (Matrix) regions. Finally, the formation mechanism of freckle near the interface is discussed.

\section{Materials and Methods}

\subsection{Selection of Superalloys}

Superalloy CM247 LC was selected for the investigation of freckle formation in this work. CM247 LC is widely used as DS and SX parts in the highest temperature parts of aero-engines. They are working under high temperature and high-speed rotating conditions. Hundreds of pieces of single crystal turbine blades are assembled in a turbofan engine on airplanes. Of course, they should be the least amount of defects as possible. Unfortunately, in past research work, freckles which appeared during directional solidification were observed on the Ni-based DS and SX turbine blades. Superalloy CM247 LC is prone to freckle formation due to the content of elements such as Rhenium, Tungsten, Titanium, and so on, which is a kind of deleterious macro-segregation defect.

CM247 LC is a polycrystalline cast nickel base superalloy. It is commonly produced using directional solidification techniques to improve creep rupture strength. It has exceptional high temperature strength, corrosion, and oxidation resistance. This alloy can also be obtained with hafnium additions to control the grain boundary structure; in turn, this addition prevents cracking and improves ductility during processing. CM247 LC is commonly used for blade rings and high pressure turbine blades. CM247 LC is a chemically modified superalloy derived in late 1970s from the MAR-M247 composition, specifically designed for DS blade and vane applications. The nominal composition of CM247 LC is shown in Table 1 [13]. Figure 1 [14] shows the SEM micrograph of the as-cast microstructure of CM247 LC superalloy, and $\gamma / \gamma^{\prime}$ eutectic, MC carbide, $\gamma$ matrix, and $\gamma^{\prime}$ particle were detected. 


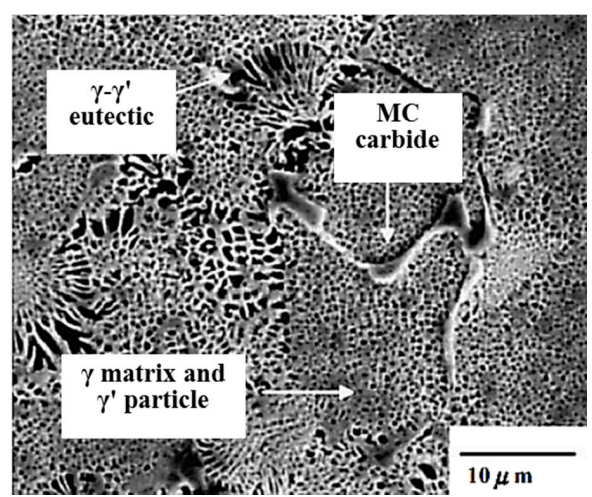

Figure 1. SEM micrograph showing the as-cast microstructure of the CM 247 LC superalloy.

Table 1. Nominal composition of the investigated superalloy CM247 LC (in wt \%).

\begin{tabular}{ccccccccccccc}
\hline Alloy & Cr & Co & Mo & W & Ta & Al & Ti & Hf & B & C & Zr & Ni \\
\hline CM247 LC & 8.1 & 9.2 & 0.5 & 9.5 & 3.2 & 5.6 & 0.7 & 1.4 & 0.015 & 0.07 & 0.015 & Bal. \\
\hline
\end{tabular}

\subsection{Specimen Design}

\subsubsection{Solid Specimens}

As shown in Table 2, a series of diameters of solid rod specimens were prepared with diameters of $5 \mathrm{~mm}, 7 \mathrm{~mm}, 9 \mathrm{~mm}, 11 \mathrm{~mm}, 13 \mathrm{~mm}, 15 \mathrm{~mm}$, and $19 \mathrm{~mm}$. Figure 2a shows the 3D design of a series of solid rod specimens, and in the bottom of the specimen, a kind of helix (spiral crystal selector) was used for the single crystal growth, with a height of $65 \mathrm{~mm}$ and a 360 degree helix angle. The height of the rod specimens was $150 \mathrm{~mm}$, and the cross sectional areas were $20 \mathrm{~mm}^{2}, 39 \mathrm{~mm}^{2}, 64 \mathrm{~mm}^{2}, 95 \mathrm{~mm}^{2}$, $133 \mathrm{~mm}^{2}, 177 \mathrm{~mm}^{2}$ and $283 \mathrm{~mm}^{2}$, respectively. The wax specimens were assembled around a central rod, in a cluster on a wax disk.

Table 2. Solid specimens in diameter $(\mathrm{mm})$ and cross sectional area $\left(\mathrm{mm}^{2}\right)$.

\begin{tabular}{cccccccc}
\hline Specimen No. & $\mathbf{1}$ & $\mathbf{2}$ & $\mathbf{3}$ & $\mathbf{4}$ & $\mathbf{5}$ & $\mathbf{6}$ & $\mathbf{7}$ \\
\hline Diameter $(\mathrm{mm})$ & 5 & 7 & 9 & 11 & 13 & 15 & 19 \\
Cross Sectional area $\left(\mathrm{mm}^{2}\right)$ & 20 & 39 & 64 & 95 & 133 & 177 & 283 \\
\hline
\end{tabular}

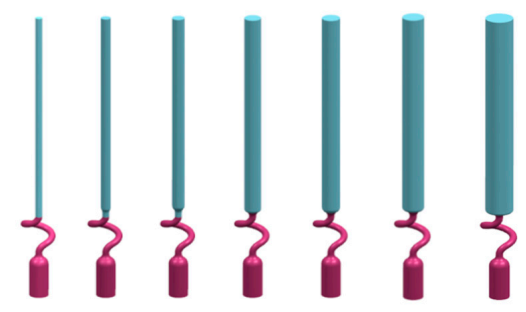

(a)

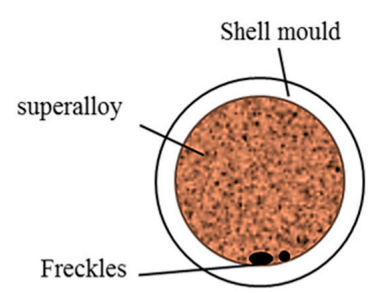

(b)

Figure 2. Schematic diagram of (a) 3D design of a series of solid rod specimens, and (b) possible freckle formation on the external surface.

\subsubsection{Multi-Interface Specimens}

With the increasing demand of the aerospace industry, more and more large and complex superalloy components are required for airplane engines. The complex components, especially ceramic cores, are applied in the hollow blades that cause multi-interfaces in the casting specimens. 
In the present work, it was observed that the freckle defects occurred near the interfaces of superalloys and ceramic materials, as shown in Figure 3a. Indeed, this is the first time that the freckle defects occurred near the interface of the superalloys and ceramic core inside of casting specimens. Furthermore, due to the arrangement of the specimen on the disc in the Bridgman furnace, shown in Figure $3 b$, the freckle was observed on the shadow side of the specimens, which face the central rod and have a lower temperature than the heater side. A schematic diagram of the freckle defects that occur near the multi-interfaces is shown in Figure 3a; the dark parts are superalloys, and the white parts are ceramic materials (ceramic core inside of the casting or alumina shell mold outside of the casting). Because of the ceramic materials, there was more than one interface near the superalloys. The ceramic core inside of the casting provided an additional interface.

For simplification, ceramic tubes were used to replace the ceramic core inside of the castings. Ceramic tubes with various diameters were designed, to investigate their influence of interface effects to freckling (Figure 3). The size of the ceramic tube and external diameter of the specimen are shown in Table 3.

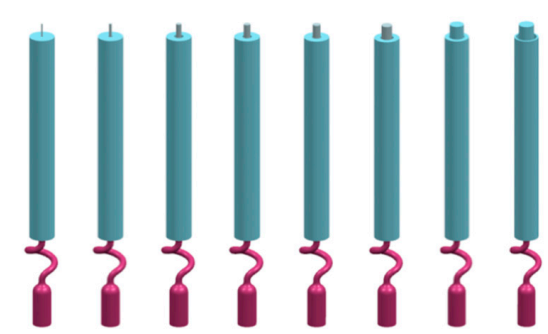

(a)

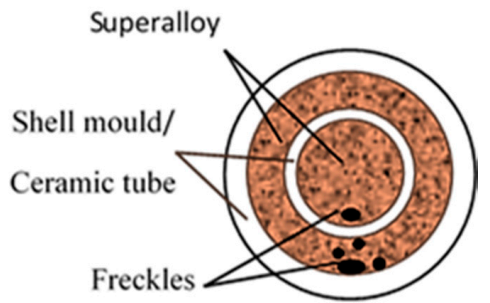

(b)

Figure 3. Schematic diagram of (a) 3D design of a series of rod specimens with multi-interfacial features and $(\mathbf{b})$ possible freckle formation on the multi-interfaces.

Table 3. Specimens with multi-interfacial features in diameter $(\mathrm{mm})$ and cross sectional area $\left(\mathrm{mm}^{2}\right)$.

\begin{tabular}{ccccccccc}
\hline Specimen No. & $\mathbf{1}$ & $\mathbf{2}$ & $\mathbf{3}$ & $\mathbf{4}$ & $\mathbf{5}$ & $\mathbf{6}$ & $\mathbf{7}$ & $\mathbf{8}$ \\
\hline External diameter $(\mathrm{mm})$ & 19 & 19 & 19 & 19 & 19 & 19 & 19 & 19 \\
Internal diameter $(\mathrm{mm})$ & 1 & 2 & 4 & 5 & 6 & 8 & 11 & 12 \\
Internal cross sectional area $\left(\mathrm{mm}^{2}\right)$ & 0.8 & 3 & 13 & 20 & 28 & 50 & 95 & 113 \\
\hline
\end{tabular}

\subsection{Procedure of Directional Solidification}

During the casting progress, the ceramic shell mold (See Figure 4a) was placed on the copper chill plate in the Bridgman furnace shown in Figure $4 \mathrm{~b}$. The shell mold was preheated, poured with the superalloy melt (See Figure 4c), and then withdrawn from the heating zone through the baffle into the cooling zone, shown in Figure $4 \mathrm{~d}$. The employed heater and pouring temperatures were $1450{ }^{\circ} \mathrm{C}$ and $1500{ }^{\circ} \mathrm{C}$, respectively. The single crystal solidification of the components was achieved by a grain selector. A low withdrawal velocity of $v=1.0 \mathrm{~mm} / \mathrm{min}$ was applied to promote freckle defects.

The solidification experiments with superalloy CM 247 LC were carried out in a Bridgman furnace with a low temperature gradient $(2.0$ to $5.0 \mathrm{~K} / \mathrm{mm})$ and a withdrawal velocity of $1.0 \mathrm{~mm} / \mathrm{min}$. The temperature of the two annular upper and lower heating elements in the vacuum Bridgman furnace are shown in Figure 5. Heating temperature was controlled accurately by two annular upper and lower heating elements. The heating rate is $20 \mathrm{~K} / \mathrm{min}$ in the range of 800 to $1450{ }^{\circ} \mathrm{C}$ during the heating process, and the shell mold heating temperature was held at $1450{ }^{\circ} \mathrm{C}$ when the specimens were moved from the hot zone to the cold zone. After mold cooling, the specimens were knocked out of the shell mold, and sand blasting was used to clean the surface. The characteristic freckle defects can be observed after macro-etching with metallographic microscope. The cooling temperature curve of the heating and the shadow side of the $\varnothing 19 \mathrm{~mm}$ casting rod (at a height of $190 \mathrm{~mm}$ from the chill plate) 
during directional solidification process is presented in Figure 6. As shown in Aune's research [15], the solidus and liquidus of alloy CM247 LC are $1282{ }^{\circ} \mathrm{C}$ and $1368{ }^{\circ} \mathrm{C}$, respectively. Therefore, the cooling rate of the heating side and the shadow side of the $\varnothing 19 \mathrm{~mm}$ casting rod are $1.8 \mathrm{~K} / \mathrm{min}$ and $1.7 \mathrm{~K} / \mathrm{min}$, respectively.

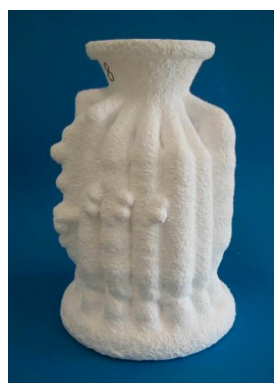

(a)

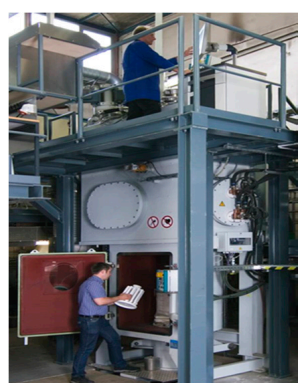

(b)

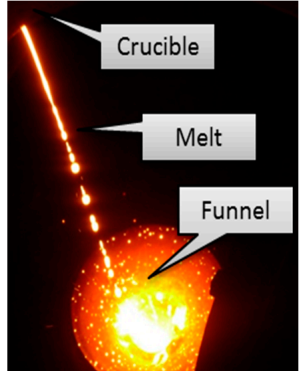

(c)

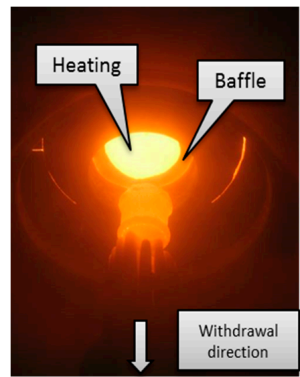

(d)

Figure 4. The process of directional solidification in the industrial vacuum Bridgman furnace: (a) Shell mold; (b) mold loaded in the Bridgman furnace; (c) melt pouring, and (d) directionally solidification and mold cooling.

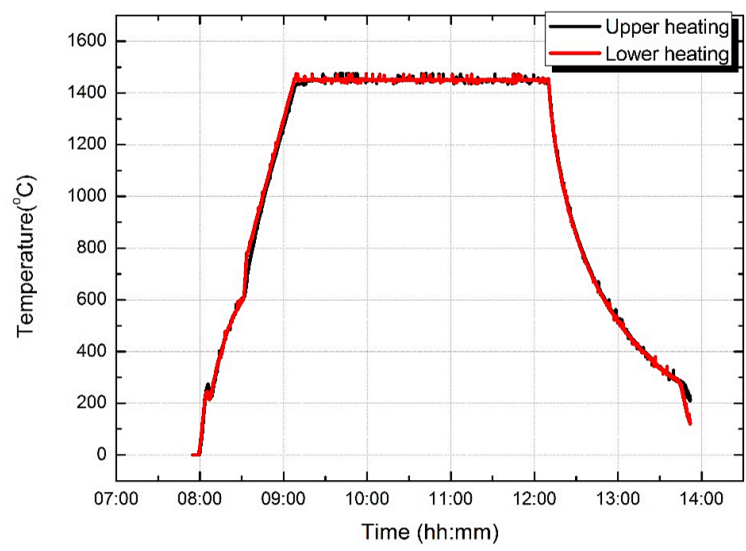

Figure 5. The temperature of the heating system during the solidification and cooling process in the Bridgman furnace.

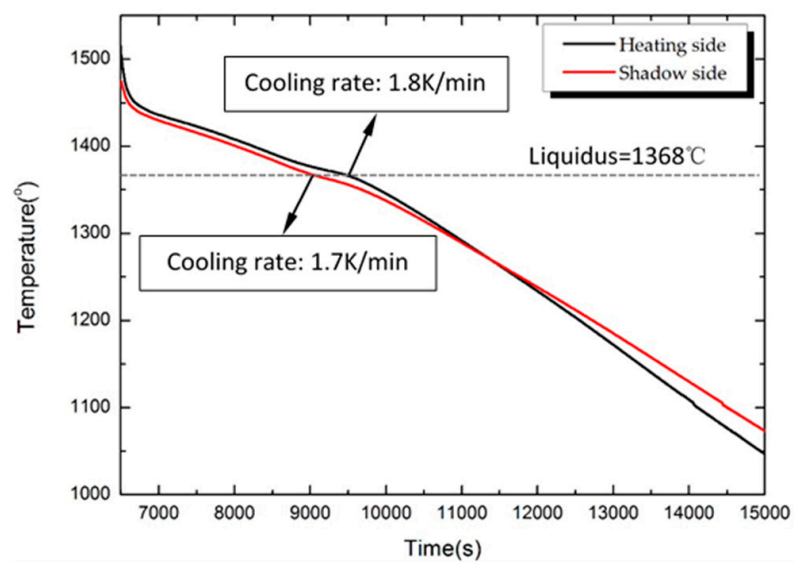

Figure 6. The temperature of the heating and the shadow side of the $\varnothing 19 \mathrm{~mm}$ rod during the solidification and cooling process (at a height of $190 \mathrm{~mm}$ from the chill plate). 


\subsection{Metallographic and Composition Analysis}

A series of rods with varying diameters were directionally solidified in the cluster mold in an industrial Bridgman furnace. After cooling and being knocked out of the shell mold, the rods were cut off from the casting cluster and sand blasted to remove any residue on the surface. Macro-etching examination with a solution of $50 \mathrm{pct} \mathrm{H}_{2} \mathrm{O}_{2}$ and $50 \mathrm{pct} \mathrm{HCl}$, and a micro-etching in a solution of 60 pct alcohol, 40 pct $\mathrm{HCl}$, and $2 \mathrm{~g} \mathrm{Cu}_{2} \mathrm{Cl} \cdot 2 \mathrm{H}_{2} \mathrm{O}$ was employed to determine whether and where freckles were present in the casting rods.

The microstructures of the freckles on the single crystal superalloy components were characterized by optical microscopy (OM) and scanning electron microscopy (SEM). The compositions in the matrix and freckle regions of the as-cast CM247 LC were determined by energy dispersive X-ray analysis (EDS).

\section{Results}

\subsection{Freckle Occurrence on the External Surface}

Figure 7a shows the CM247 LC rods with diameters of $5 \mathrm{~mm}, 7 \mathrm{~mm}, 9 \mathrm{~mm}, 11 \mathrm{~mm}, 13 \mathrm{~mm}$, and $15 \mathrm{~mm}$ after macro-etching. The freckle chains (Figure $7 \mathrm{~b}$, in bright and gray colors) on the surface were parallel to the solidification direction. The freckles occurred on the external surface of all of the rods with cross sectional areas of $20 \mathrm{~mm}^{2}, 39 \mathrm{~mm}^{2}, 64 \mathrm{~mm}^{2}, 95 \mathrm{~mm}^{2}, 133 \mathrm{~mm}^{2}$, and $177 \mathrm{~mm}^{2}$. Freckle chains are marked by circles in Figure 7a, and the initial position of the freckles (the height from the chill) were $189 \mathrm{~mm}, 164 \mathrm{~mm}, 172 \mathrm{~mm}, 156 \mathrm{~mm}, 158 \mathrm{~mm}$, and $155 \mathrm{~mm}$, respectively. The initial position of freckles in the $15 \mathrm{~mm}$ diameter rod was lower than the other rods with smaller cross sectional areas.

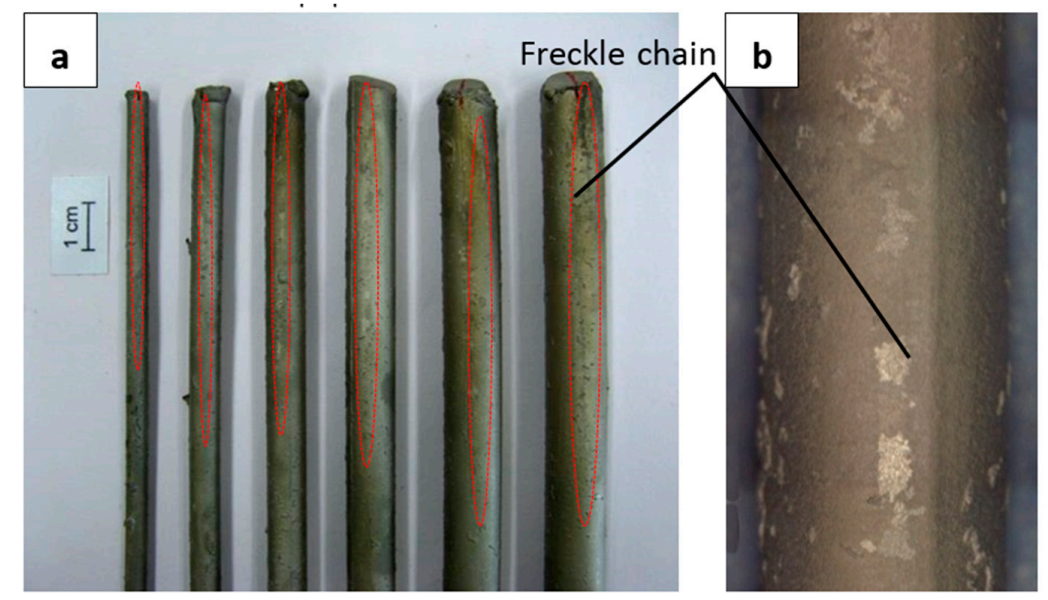

Figure 7. Freckle defects on CM247 LC casting rods with diameters of $5 \mathrm{~mm}, 7 \mathrm{~mm}, 9 \mathrm{~mm}, 11 \mathrm{~mm}$, $13 \mathrm{~mm}$, and $15 \mathrm{~mm}$ after directional solidification in a vacuum Bridgman furnace with a low withdraw rate of $1.0 \mathrm{~mm} / \mathrm{min}$. (a) freckles location; (b) magnification picture of freckles.

The cross sections containing freckle chains on the top of the CM247 LC rods (a height of $210 \mathrm{~mm}$ from the cooling chill) with diameters of $5 \mathrm{~mm}, 7 \mathrm{~mm}, 9 \mathrm{~mm}, 11 \mathrm{~mm}, 13 \mathrm{~mm}, 15 \mathrm{~mm}$, and $19 \mathrm{~mm}$ are marked by a yellow frame in Figure 8a-g under metallurgical microscopy. As shown in Figures 7b and 8 , the freckle defect is a linear trail of equiaxed grains which have different orientations, and the freckle area is reflected by different colors (in bright and gray colors), compared with the matrix area which has a single crystal structure. It appears as dark and white spots in the cross sections of the metallographs (a) to (g) in Figure 8. The area of freckles increases with increasing cross sectional area of the specimens from $20 \mathrm{~mm}^{2}$ to $283 \mathrm{~mm}^{2}$. Meanwhile, the $\gamma / \gamma^{\prime}$ eutectic phase is depicted by arrows in the freckle area, and it can be seen that the freckle area has a higher fraction of $\gamma / \gamma^{\prime}$ eutectic than the matrix. 

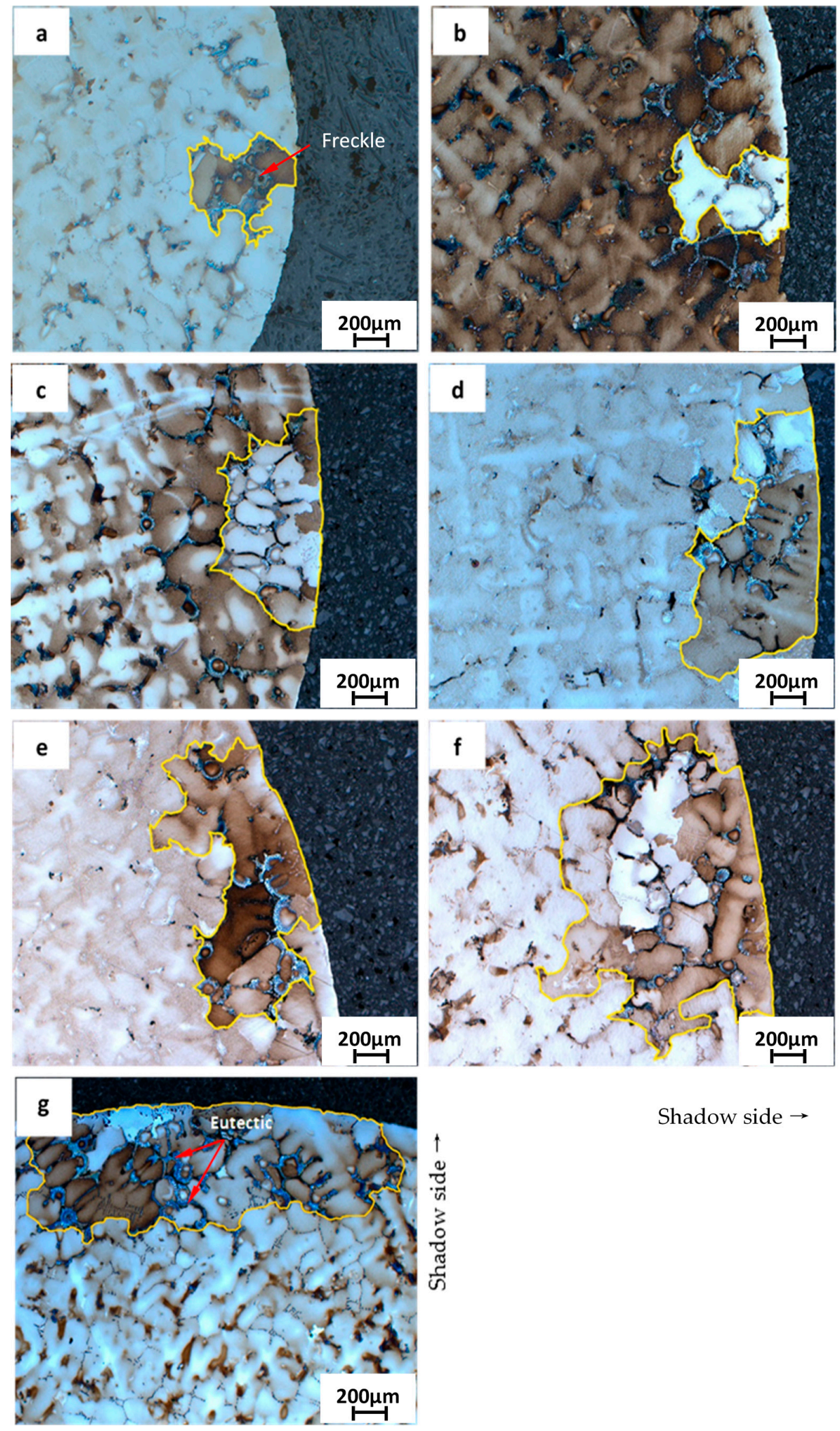

Shadow side $\rightarrow$

Figure 8. Freckle observed under metallurgical microscopy on the cross section of CM247 LC casting rods (at a height of $210 \mathrm{~mm}$ from the cooling chill) with diameters of (a) $5 \mathrm{~mm}$; (b) $7 \mathrm{~mm}$; (c) $9 \mathrm{~mm}$; (d) $11 \mathrm{~mm}$; (e) $13 \mathrm{~mm}$; (f) $15 \mathrm{~mm}$; and (g) $19 \mathrm{~mm}$. 


\subsection{Freckle Occurrence on Multi-Interfaces}

The CM247 LC casting specimen with multi-interfaces (Specimen No. 8 with an internal diameter of $12 \mathrm{~mm}$ and an external diameter of $19 \mathrm{~mm}$ ) is shown in Figure 9. After removing the shell mold material, freckle defects were observed on the cross section of the specimen. Seen in Figure 9b, the black area between the internal and external superalloy is the ceramic tube, meanwhile, the black area near the surface of the external superalloy is the shell mold. The internal and external freckle chains on the vertical direction of the specimen are shown in Figure 9a,c, which were separated from Specimen No. 8 . The freckles occurred not only on the external surface but also on the internal interface. One freckle chain was observed on the surface of the inner superalloy A, meanwhile, three freckle chains on the outer superalloy B were observed at the low height position from the cooling chill, and three freckle chains converged to one chain at the higher position from the cooling chill. Figure $9 \mathrm{~b}$ indicates that freckles near the inner-interface and outer-interface occurred on the shadow side, which had a lower cooling rate.

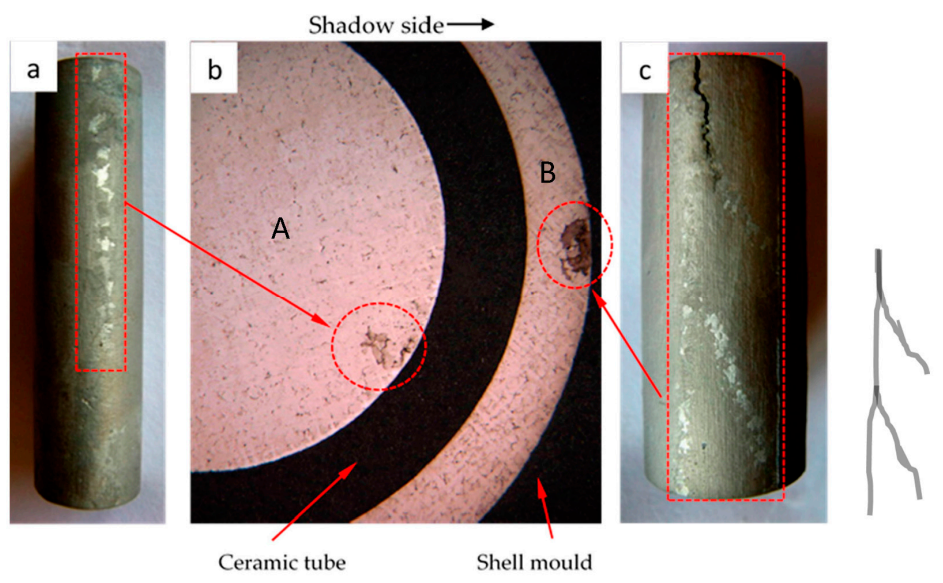

Figure 9. Freckle chain occurs on the: (a) internal surface and (b) cross section of specimen; (c) external surface of CM247 LC.

Figure 10a shows the freckles on the cross sectional surface of the inner superalloy A and Figure 10b shows the freckles on the surface of the outer superalloy B. The depth and width of the freckle chain on the surface of the outer superalloy are $1569 \mu \mathrm{m}$ and $833 \mu \mathrm{m}$, respectively. Moreover, the depth and width of the freckle chain on the surface of the inner superalloy is $1114 \mu \mathrm{m}$ and $1236 \mu \mathrm{m}$, respectively. The area of the freckles on the outer and inner superalloy is $1.01 \mathrm{~mm}^{2}$ and $0.89 \mathrm{~mm}^{2}$, respectively. It indicates that the side and area of the freckle chain on the outer superalloy $B$ is greater than that on the inner superalloy A.
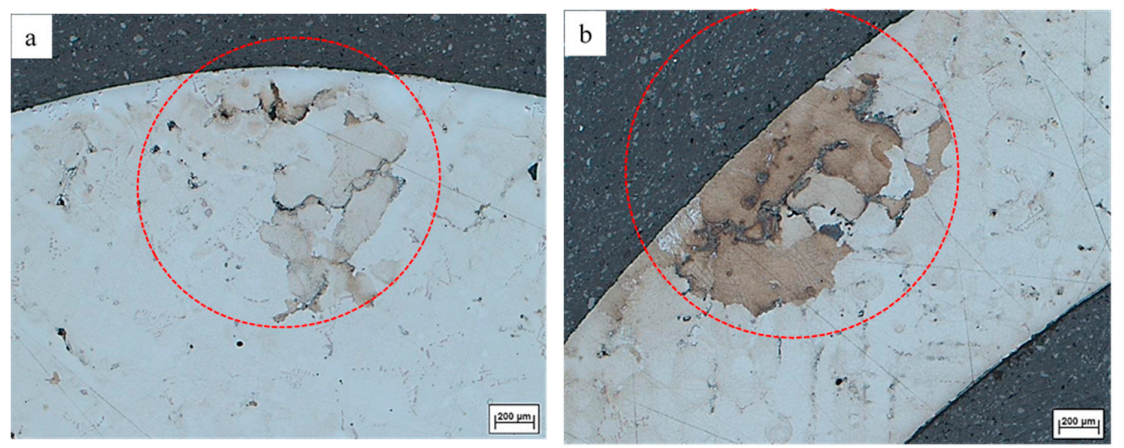

Figure 10. Magnified photos of freckles near the multi-interfaces (cross section of superalloy CM247 LC in Figure 6) on (a) the interface of the inner superalloy A and (b) the interface of the outer superalloy B. 
The cross sections at a height of $190 \mathrm{~mm}$ from the cooling chill, with various diameters of ceramic tubes, are shown in Figure 11a-h and are as follows. Freckle defects were found both near the inner-interface and outer-interface in the specimens with $11 \mathrm{~mm}$ and $12 \mathrm{~mm}$ diameters, shown in Figure 11 and Table 4. The freckle defects were observed on the shadow side of the outer-interface surface ceramic tubes with diameter of $1 \mathrm{~mm}, 2 \mathrm{~mm}, 4 \mathrm{~mm}, 5 \mathrm{~mm}, 6 \mathrm{~mm}, 8 \mathrm{~mm}, 11 \mathrm{~mm}$, and $12 \mathrm{~mm}$ inside of the specimens.

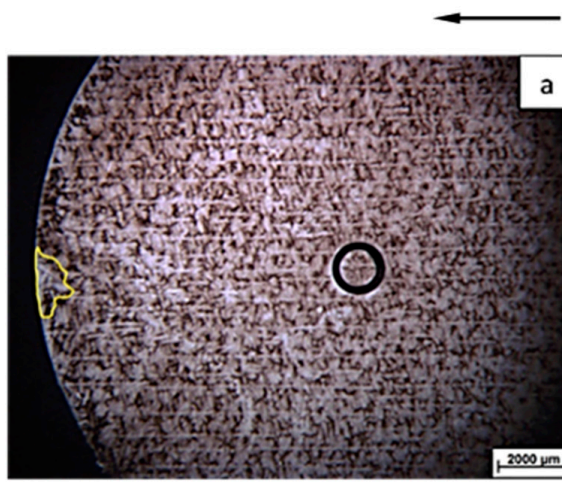

Shadow side
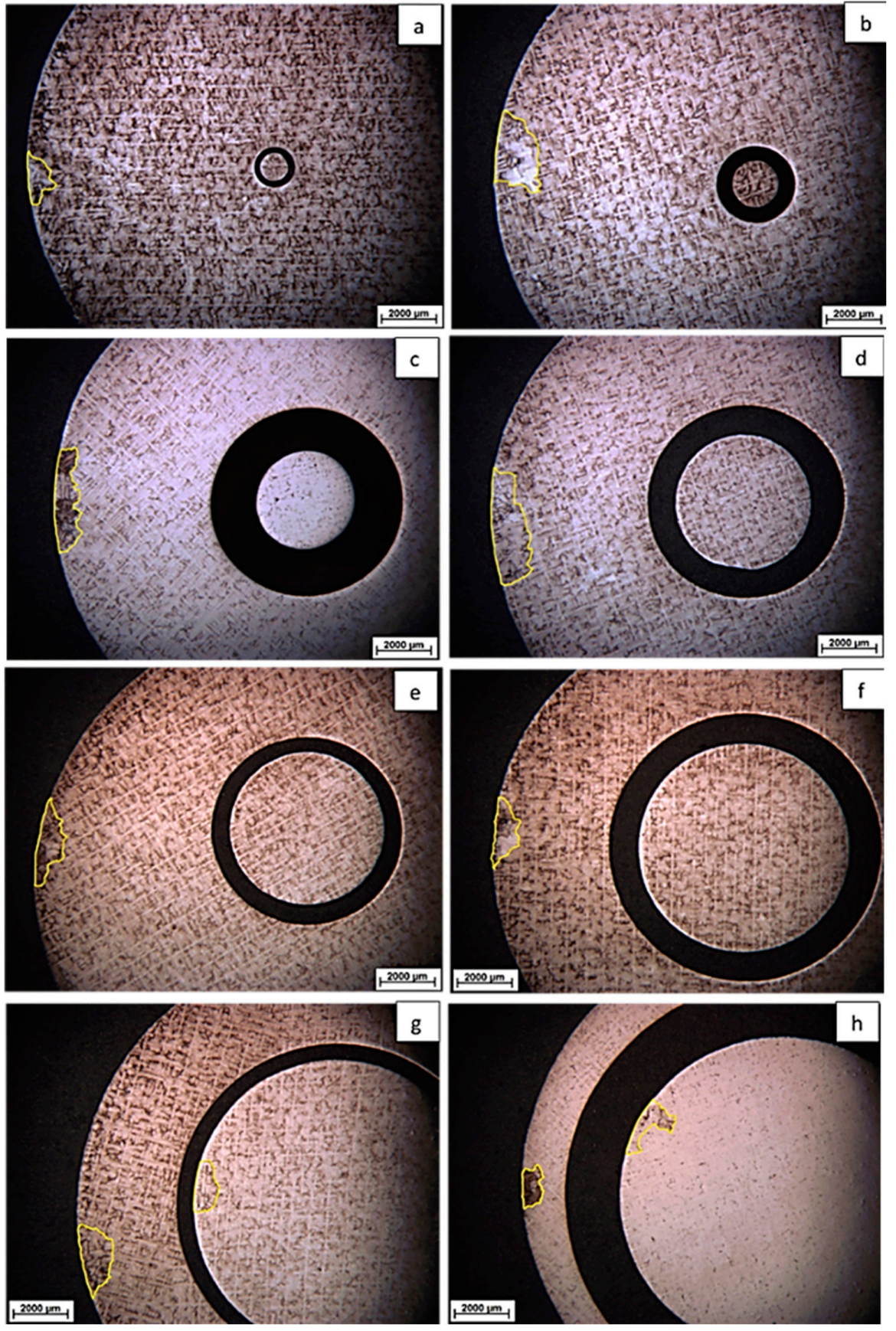

Figure 11. Freckles on the specimens with various diameters of ceramic tubes inside: (a) $1 \mathrm{~mm}$; (b) $2 \mathrm{~mm}$; (c) $4 \mathrm{~mm}$; (d) $5 \mathrm{~mm}$; (e) $6 \mathrm{~mm}$; (f) $8 \mathrm{~mm}$; (g) $11 \mathrm{~mm}$; and (h) $12 \mathrm{~mm}$. 
Table 4. Freckle statistics of a series of rod specimens with multi-interfacial features in the diameter.

\begin{tabular}{ccccccccc}
\hline Specimen No. & $\mathbf{1}$ & $\mathbf{2}$ & $\mathbf{3}$ & $\mathbf{4}$ & $\mathbf{5}$ & $\mathbf{6}$ & $\mathbf{7}$ & $\mathbf{8}$ \\
\hline External diameter $(\mathrm{mm})$ & 19 & 19 & 19 & 19 & 19 & 19 & 19 & 19 \\
Freckle? & YES & YES & YES & YES & YES & YES & YES & YES \\
Internal diameter $(\mathrm{mm})$ & 1 & 2 & 4 & 5 & 6 & 8 & 11 & 12 \\
Freckle? & NO & NO & NO & NO & NO & NO & YES & YES \\
\hline
\end{tabular}

The chemical composition of freckles on the external surface (Inspection zone A1), freckles on the internal surface (Inspection zone A2), and in the matrix (Inspection zone A3) were investigated by SEM with energy dispersive X-ray analysis (EDS), shown in Figure 9a,b. The results of the chemical composition in zones A1, A2, and A3 are shown in Figure 12c.
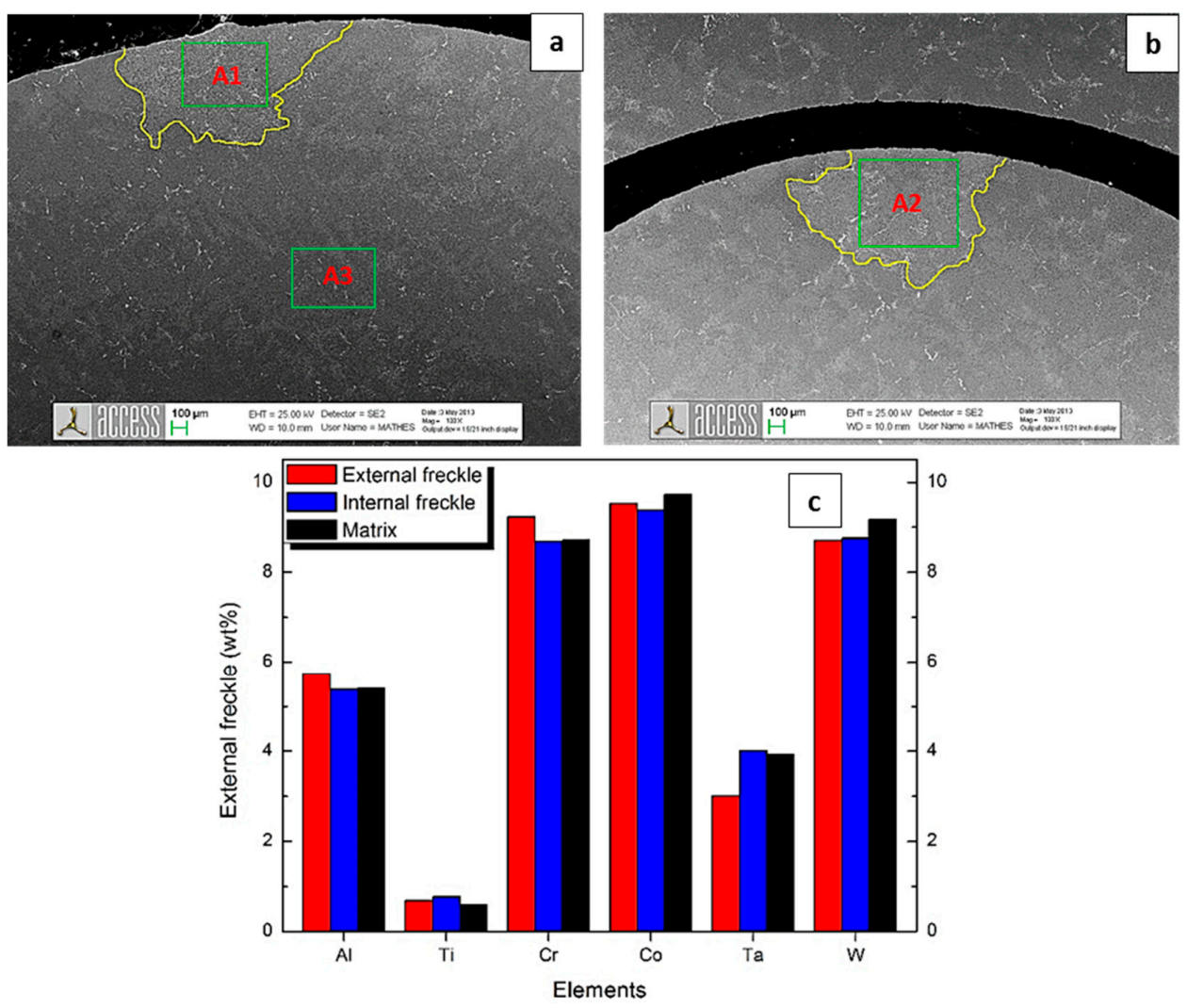

Figure 12. Composition (in wt \%) in the matrix and freckle area of as-cast CM $247 \mathrm{LC}$ with a $11 \mathrm{~mm}$ diameter ceramic tube inside, by SEM with EDS: (a) Inspection zone A1 is the external freckle area, Inspection zone A3 is the matrix area; (b) Inspection zone A2 is the internal freckle area; (c) EDS results.

\section{Discussion}

\subsection{Influence of Height from Cooling Chill}

Based on the present experiments and past research [16], freckles do not occur on the bottom of rods immediately, but start from a particular height from the cooling chill. Metallographic analysis was carried out by cutting the samples at heights of $110 \mathrm{~mm}, 150 \mathrm{~mm}, 190 \mathrm{~mm}$, and $210 \mathrm{~mm}$ from the cooling chill, which is perpendicular to the solidification direction, shown in Figure 13. Freckles were observed on the cross section a (height of $210 \mathrm{~mm}$ ) and cross section b (height of $190 \mathrm{~mm}$ ) on the shadow side in the furnace, and no freckle was observed on the section a (height of $150 \mathrm{~mm}$ ) and section $b$ (height of $110 \mathrm{~mm}$ ). 
Shadow side
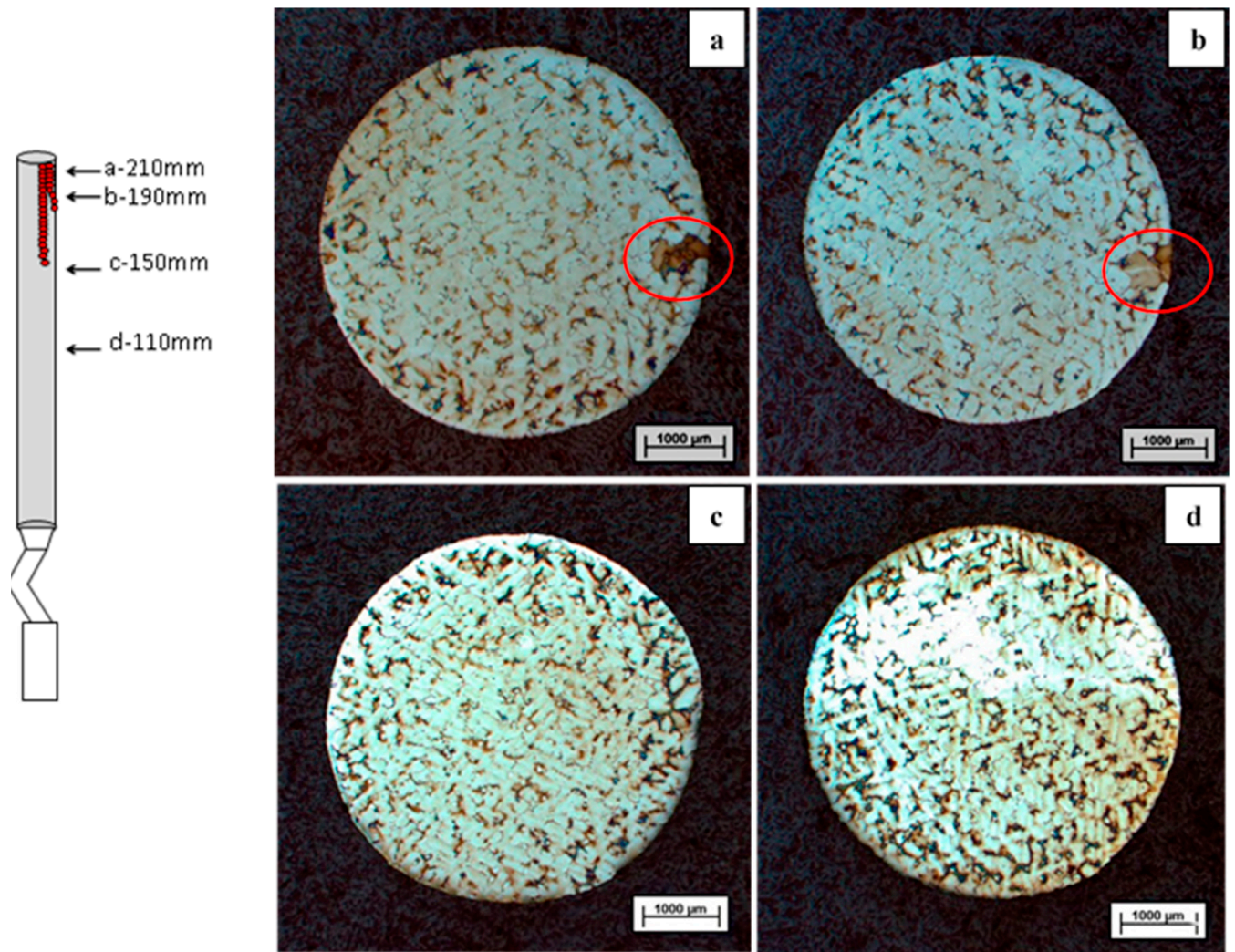

Figure 13. Cross sections of CM247 LC at different heights from the cooling chill (with a $5 \mathrm{~mm}$ diameter), freckles were observed above a height of $150 \mathrm{~mm}$ from the chill plate: (a) height of $210 \mathrm{~mm}$; (b) height of $190 \mathrm{~mm}$; (c) height of $150 \mathrm{~mm}$; (d) height of $110 \mathrm{~mm}$.

Moreover, the height of initiation position of the freckle chain reduces when the diameter of rod increases. As shown in Figure 14, the height of freckle initiation position was $178.9 \mathrm{~mm}$ with a diameter of $5 \mathrm{~mm}$, but it decreased to $152.6 \mathrm{~mm}$ with a diameter of $19 \mathrm{~mm}$. In the same solidification condition, large diameter specimens have a higher probability and less incubation height of freckle formation. It is indicated that the initiation position and average size of the freckle chain are relative with rod diameter in the same solidification process.

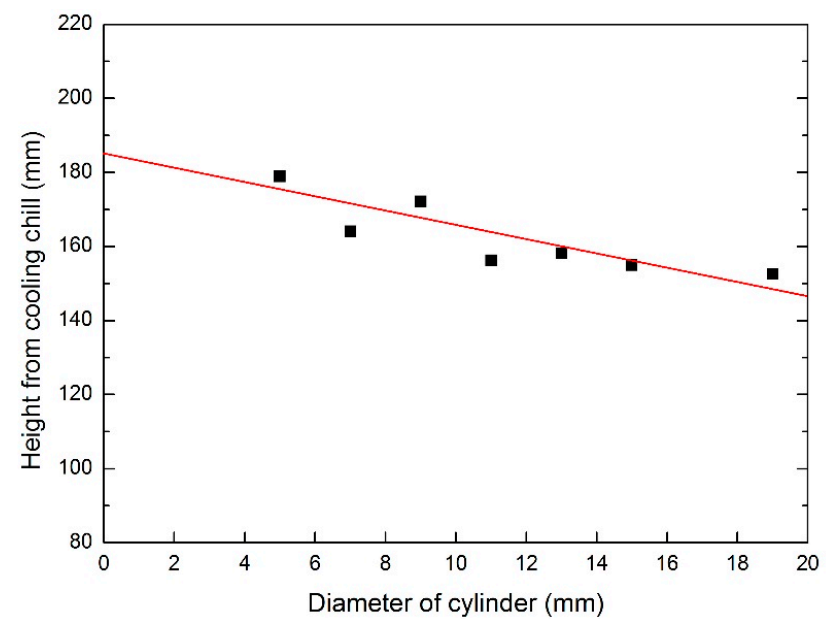

Figure 14. Initiation position of the freckle chain in various diameters. 
In Figure 15, the maximum and minimum width of freckle chains on the specimens was measured using a metalloscope. It indicated that the maximum and minimum width of freckle chain increases when the diameter of the rod increases. The maximum width of the freckle chain is $0.94 \mathrm{~mm}$ when the diameter is $5 \mathrm{~mm}$, but it rises to $5.12 \mathrm{~mm}$ when the diameter is $19 \mathrm{~mm}$. The minimum width of the freckle chain is $0.40 \mathrm{~mm}$ when the diameter is $5 \mathrm{~mm}$, and it rises to $1.90 \mathrm{~mm}$ when the diameter is $19 \mathrm{~mm}$.

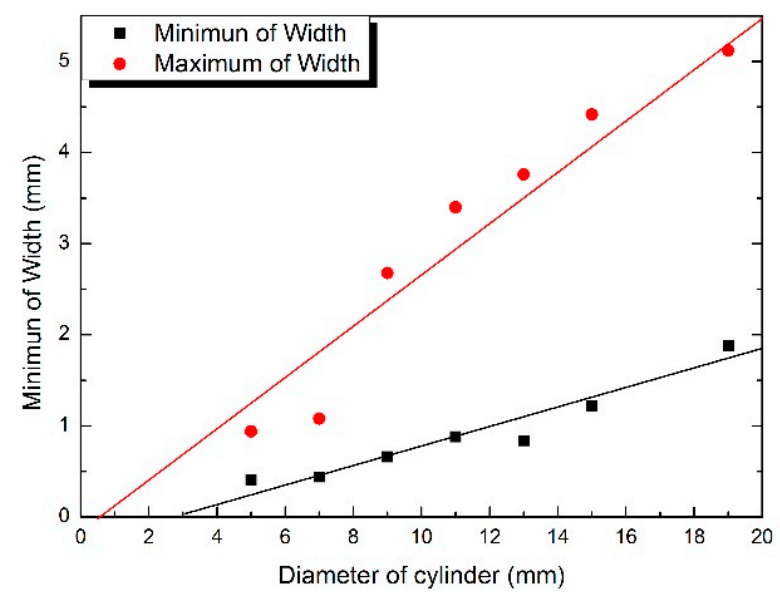

Figure 15. Statistics of the maximum and minimum width of freckle chains with incremental diameter of the specimens.

Specimens were cut-up as cross sections near the initiation position, and the primary dendrite arm spacing (PDAS, $\lambda_{1}$ ) was measured and calculated using image processing software. It indicated that the primary dendrite arm spacing of incremental diameter (incremental cross sectional area) follows the linear relationship in Figure 16. The dot is the experimental date and the red line indicates linear fitting of the primary dendrite arm spacing as a function of the diameter. The fitting equation is $y=374.2+9.07 x$. The Rayleigh number developed by Sarrazin and Hellawell could be written as follows [17]:

$$
R_{a}=\frac{g \frac{d \rho}{d T}}{\eta D_{T}} \times G \lambda_{1}^{4}
$$

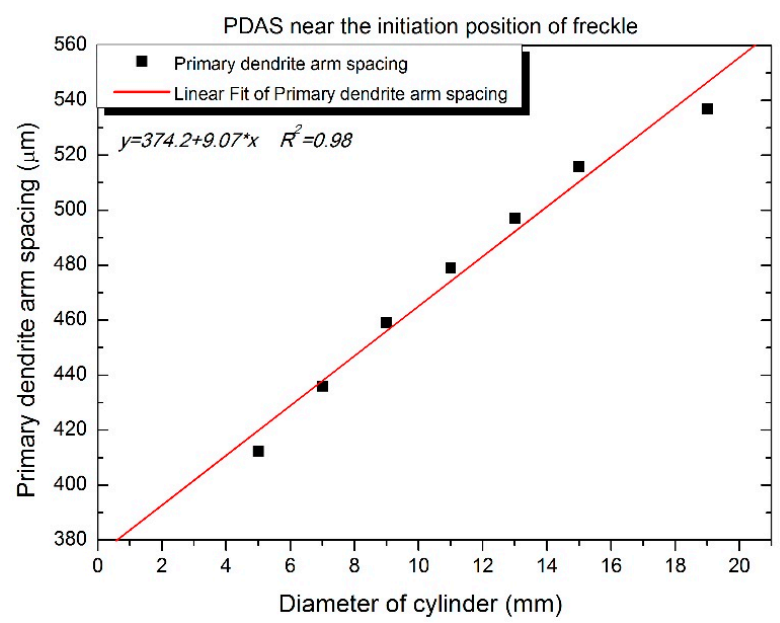

Figure 16. Experimental date and the fitting line of the primary dendrite arm spacing $\left(\lambda_{1}\right)$ at the height of the freckle initiation position with diameters of $5 \mathrm{~mm}, 7 \mathrm{~mm}, 9 \mathrm{~mm}, 11 \mathrm{~mm}, 13 \mathrm{~mm}, 15 \mathrm{~mm}$, and $19 \mathrm{~mm}$. 
As the primary dendrite arm spacing $\left(\lambda_{1}\right)$ increases, the Rayleigh number $\left(R_{a}\right)$ increases. The tendency of freckle formation would be promoted when $R_{a}$ increases. The result in Figure 16 agrees with the Rayleigh number criterion that freckle chain occurs preferentially in the large size rods because it has a greater $\lambda_{1}$, which means that freckle chain has more space and less resistance from liquid in the interdendritic area in the mushy zone.

\subsection{Influence of Cross Sectional Area}

The area and area percentage of freckles on the cross sections shown in Figure 8a- $\mathrm{f}$ were measured. As shown in Figure 17, the area of freckles on the top were $0.26 \mathrm{~mm}^{2}, 0.38 \mathrm{~mm}^{2}, 0.67 \mathrm{~mm}^{2}, 0.97 \mathrm{~mm}^{2}$, $1.29 \mathrm{~mm}^{2}, 1.90 \mathrm{~mm}^{2}$, and $3.39 \mathrm{~mm}^{2}$ which follows the linear relationship with the cross sectional area of $20 \mathrm{~mm}^{2}, 39 \mathrm{~mm}^{2}, 64 \mathrm{~mm}^{2}, 95 \mathrm{~mm}^{2}, 133 \mathrm{~mm}^{2}, 177 \mathrm{~mm}^{2}$, and $284 \mathrm{~mm}^{2}$, respectively. The area of freckles increases when the cross sectional area increases.

As shown in Figure 16, when the primary dendrite arm spacing $\left(\lambda_{1}\right)$ increases, the Rayleigh number $\left(R_{a}\right)$ also increases, which has a higher tendency of defect formation. However, there is no significant change in the area percentage of freckles when the cross sectional area increases; it maintains a constant level, and the average value of the area percentage of freckles was $1.1 \%$ of the cross sectional area, shown in Figure 18.

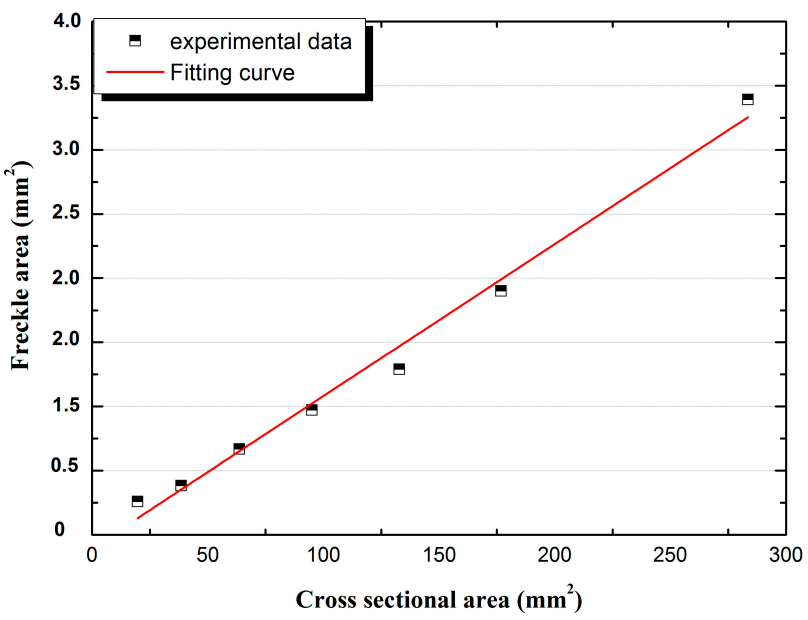

Figure 17. Freckle area and fitting curve on the top of CM247 LC rods for various cross sectional areas from 20 to $284 \mathrm{~mm}^{2}$.

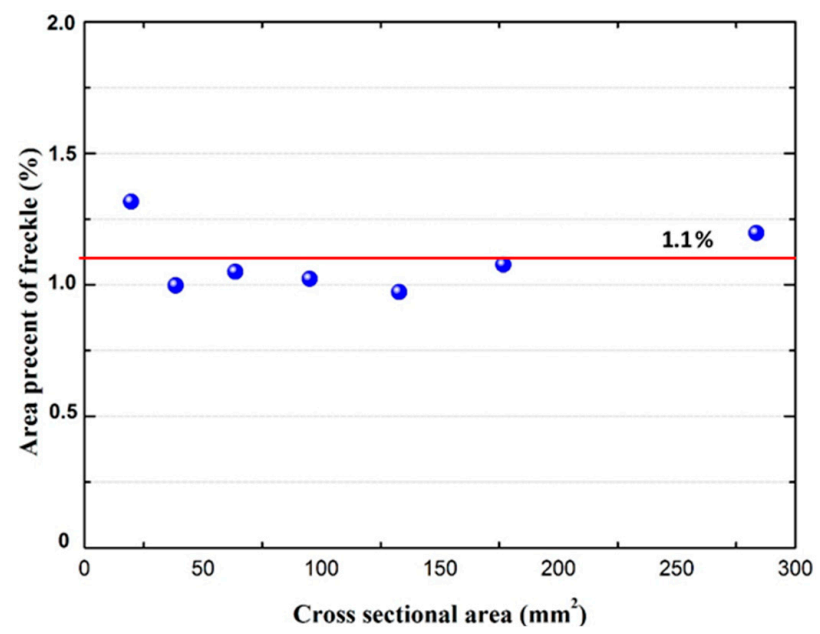

Figure 18. Freckle area percentage and fitting curve on the top of CM247 LC rods for various cross sectional areas from 20 to $284 \mathrm{~mm}^{2}$. The average value is $1.1 \%$ from this figure. 


\subsection{Interface Effects of Freckle Formation}

In the present work, ceramic cores inside of the shell mold created new interfaces in the casted parts. As the results in Figures 8 and 11 show, freckle defects were observed only on the shadow side which faced the center rod, however, no freckle defects were present on the heating side which faced the heating ring in this work. The shadow-heating effect leads to the inclination of primary dendrites during directional solidification. Brewster G. and Dong H.B. indicated that the increased micro-segregation at the surface is the inclination of the primary dendrite stem with respect to the mold wall $[18,19]$. As shown in Figure 19, extensive branching of the secondary arms on the diverging side, and the subsequent formation of tertiary arms to become new primary stalks, occurs to fill the open body of liquid at the groove at the mold wall (near the left side of the mold wall in Figure 19). Consequently, dendrite inclination could potentially lead to the formation of surface eutectic. Meanwhile, micro-segregation in the mushy zone caused density inversion near the interface of the mold wall and casting on the shadow side.

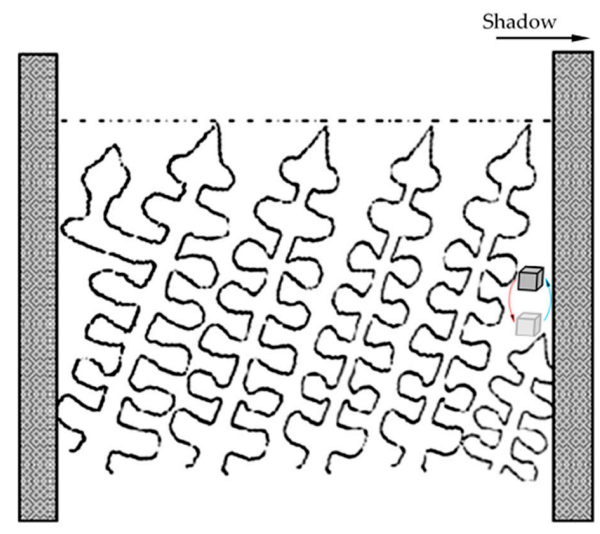

Figure 19. Schematic diagram of the inclination of the primary dendrites with respect to the mold wall. Micro-segregation causes density inversion near the interface of the mold wall and casting on the shadow side.

As shown in Figure 11, freckle defects occurred near both the internal and external interfaces if the height and specimen section size were in the range of freckle tendency. In the previous work [20-26], freckle chains were observed inside superalloy parts, especially in the center to mid-radius of VAR/ESR ingots and superalloy billets. A model sketch of freckle formation and the associated fluid flow pattern for internal freckles was applied in Figure 20a. Freckle defects were caused by fluid flow named thermosolutal convection, originating in the interdendritic region of the mushy zone during solidification. The Rayleigh number can be used to predict freckle formation with good precision, and combines alloy effects and solidification conditions. In Figure 20a, the freckle chain is surrounded by dendrites, so the resistance of fluid flow comes from the surrounding dendrites forest in the mushy zone. This kind of flow was driven by the density inversion occurring as a result of micro-segregation, as shown in Figure 19. The fluid flow rate in the interdendritic region can be obtained from Darcy's law, and the driving force $\left(F_{1}\right)$ of the fluid flow came from the density difference and gravity. The permeability of the mushy zone is a function of $\lambda_{1}, \lambda_{2}$, and the liquid fraction $f_{L}$, so the permeability where freckles occurred inside of superalloy parts is defined as [27-29]:

$$
\Pi=\Pi\left(f_{L}\right) * \Pi\left(\lambda_{1} * \lambda_{2}\right)=K_{p} * f_{L}^{a} * \lambda_{1}^{b} * \lambda_{2}^{c}
$$

where $\Pi$ is the permeability, $\lambda_{2}$ is the second dendrite arm space (SDAS), and $K_{p}$ is a constant.

Therefore, the Rayleigh number could be written as:

$$
R a=g * \frac{\rho * \Pi\left(f_{L}\right)}{v * f_{L}} * \frac{\Pi\left(\lambda_{1} * \lambda_{2}\right)}{R} * \sin \alpha * \cos (\varnothing+\alpha)
$$


As shown in Figure 20a, where $\Delta F(\rho)$ is the buoyancy force of the density difference in the mushy zone, $\Delta \mathrm{mg}$ is the dead weight of the fluid, and $f_{1}$ is the resistance of fluid flow from the surrounding the dendrites forest. Hence, the driving force $F_{1}$ is defined as:

$$
F_{1}=F(\rho)-\mathrm{mg}-f_{1}
$$

A new sketch of freckle formation and associated fluid flow pattern for freckles near the interface was applied in Figure 20b. The permeability $\Pi_{1}$ where freckles occurred near both of the internal and external interfaces of superalloy parts is defined as:

$$
\Pi_{1}=A * K_{p} * f_{L}^{a} * \lambda_{1}^{b} * \lambda_{2}^{c}
$$

where $\Delta F(\rho)$ is the buoyancy force of the density difference in the mushy zone, $\Delta \mathrm{mg}$ is the dead weight of the fluid, and $f_{2}$ is the resistance of fluid flow from the surrounding the dendrites forest. So, the driving force $F_{2}$ in this condition is defined as:

$$
F_{2}=F(\rho)-\mathrm{mg}-f_{2}
$$

where $A$ is a constant related to the surrounding dendrite forest, with a value range of $1>A>0$. Equation (5) is developed from Equation (2) based on the location of freckle occurrence. It is clear that the permeability $\Pi_{1}$ is less than $\Pi$, therefore, $f_{2}<f_{1}, F_{2}>F_{1}$, and it has more freckle tendency near the interface rather than inside the parts. Supported by this work, freckles are observed near the interfaces in most situations. The liquid flow easily moved because the flow was not completely surrounded by dendrites; more than half of the space was instead a relatively smooth surface of ceramic materials. The resistance of the ceramic materials' surface is less than in the interdendritic region, which was completely surrounded by dendrites. The flow of metal liquid near the interfaces was stronger than in the interdendritic region in the mushy zone.
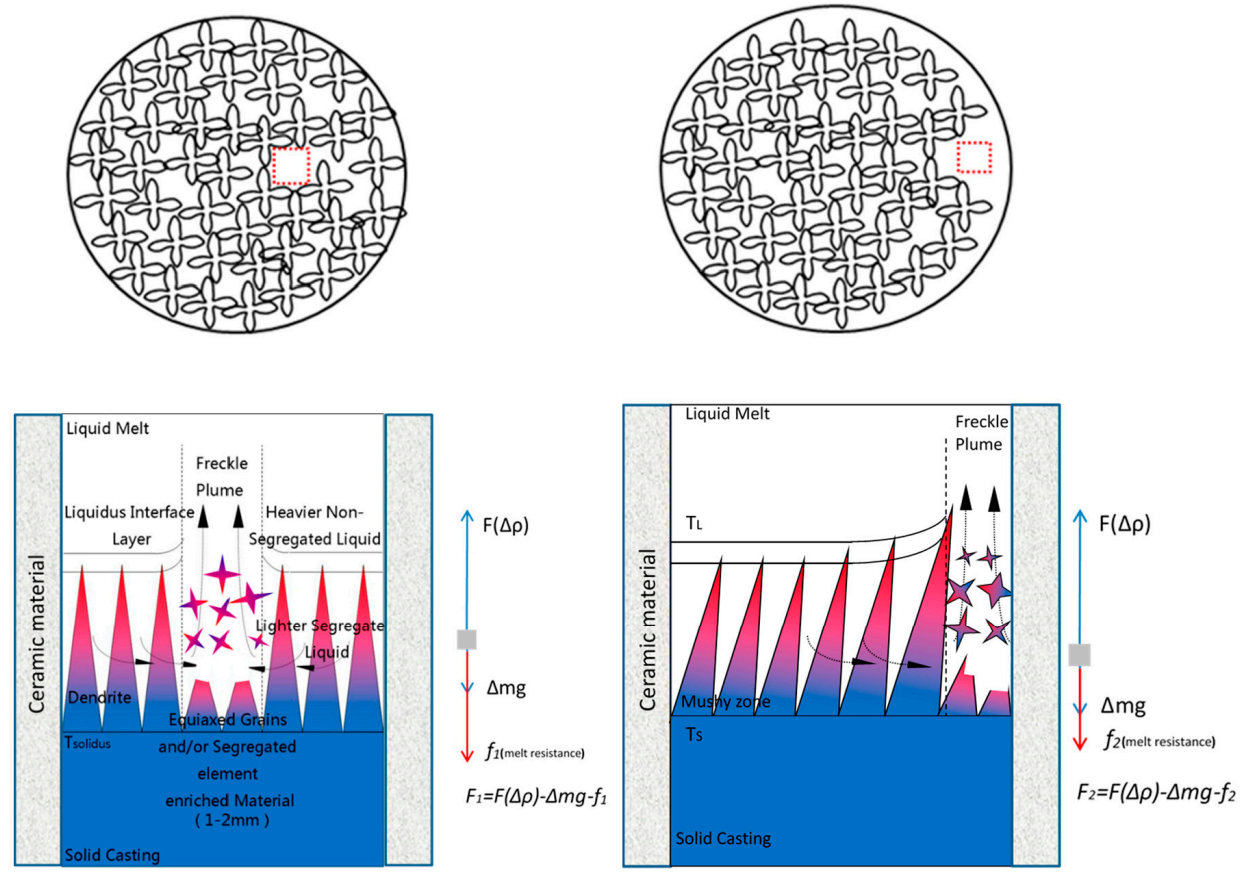

(a)

$$
f_{1}>f_{2} \quad \rightarrow \quad F_{1}<F_{2}
$$

(b)

Figure 20. Schematic diagram of freckle formation (a) inside of superalloy and (b) near the interfaces of superalloys and ceramic materials. 


\section{Conclusions}

The results indicated an interesting phenomenon, even though in the invariable casting condition and superalloy components, most of the freckle chains were observed on the shadow side and near the interface of the superalloys and ceramic materials. In this work, freckles occurred on the external surface near the interface of the superalloys and shell mold wall, or occurred on the internal surface near the interface of the superalloys and the wall of ceramic materials inside of the castings. Furthermore, the initiation position of freckle formation occurred with some regularity, and the height of the freckle initiation position from the cooling copper chill reduced from small cross section to large cross section in a series of rods with varying diameters (from $\varnothing 5 \mathrm{~mm}$ to $19 \mathrm{~mm}$ in diameter). This new phenomenon provides a reminder that freckles are more likely to occur near the interfaces if ceramic cores are used for the hollow turbine blade process.

In the present work, the specimens with multi-interfaces were directional solidified. Freckle formation near the interface of multi-interfaces of the superalloy was investigated. The conclusions are as follows:

1. Freckle defects do not only occur on the external surface of Ni-based superalloys castings, but also on the internal surface, near the interface of superalloys and ceramic materials.

2. The height of the initiation position of the freckle chain reduces when the rod diameter increases. Meanwhile, the size of the freckle chain increases when rod diameter increases.

3. Freckle area on the rod follows a linear relationship with the cross sectional area. However, there is no significant change of the area percentage of freckles, and the average value is $1.1 \%$ of the cross sectional area.

4. Freckle defects occur on the large size internal superalloy parts (Diameter of $11 \mathrm{~mm}$ and $12 \mathrm{~mm}$ ), but not on the small sizes (1 to $8 \mathrm{~mm}$ ).

Acknowledgments: The authors are grateful to Sebastian Fischer, Samuel Bogner, Elke Schaberger-Zimmermann, Elke Breuer, and Dietmar Lembrecht for their assistance with specimen preparation and metallurgical analysis. The authors gratefully acknowledge the financial support from Deutsche Forschungsgemeinschaft through the project of Untersuchung der Frecklesbildung in gerichtet erstarrten Superlegierungen (Grant No. BU1072/15-1 and -2) and the Shanghai Science and Technology Committee (Grant No. 14521102902). Jianping Hong would like to acknowledge the China Scholarship Council (CSC) for supporting his doctoral study at the Foundry Institution of RWTH Aachen University, Germany.

Author Contributions: Jianping Hong and Dexin Ma. conceived and designed the experiments; Jianping Hong, Jun Wang, and Fu Wang analyzed the data; Jianping Hong wrote the paper; Fu Wang developed the composites; Jianping Hong and Fu Wang developed the methodology of the microbiological tests; Jianping Hong performed the microbiological tests; and Baode Sun, Fei Li, and Andreas Bührig-Polaczek contributed as manuscript advisors. Each contributor was essential to the production of this work.

Conflicts of Interest: The authors declare no conflict of interest.

\section{References}

1. Bradley, E.F. Source Book on Materials for Elevated-Temperature Applications; American Society for Metals: Metals Park, OH, USA, 1969; pp. 275-298.

2. Sabol, G.P.; Stickler, R. Microstructure of nickel-based superalloys. Phys. Status Solidi B 1969, 35, 11-52. [CrossRef]

3. Jena, A.K.; Chaturvedi, M.C. The role of alloying elements in the design of nickel-base superalloys. J. Mater. Sci. 1984, 19, 3121-3139. [CrossRef]

4. Bradley, E.F. Superalloys: A Technical Guide; ASM International: Metals Park, OH, USA, 1988.

5. Kotval, P.S. The microstructure of superalloys. Metallography 1969, 1, 251-285. [CrossRef]

6. Sims, C.T. Superalloys: Genesis and Character. In Superalloys II; Sims, C.T., Stoloff, N.S., Hagel, W.C., Eds.; John Wiley \& Sons: Hoboken, NJ, USA, 1987; pp. 3-21.

7. Gao, S.; Liu, L.; Hu, X.; Ge, B.; Zhang, J.; Fu, H. Review of Freckle Defects under Directional Solidification of Nickel-based Superalloys. J. Mater. Sci. Eng. 2010, 28, 145-151. 
8. Ronan, K. A statistical analysis of variations in hot tear performance and microporosity formation versus composition in investment cast FSX-414. In Superalloys 2008; The Minerals, Metals \& Materials Society: Pittsburgh, PA, USA, 2008; pp. 157-166.

9. Yang, X.L.; Dong, H.B.; Wang, W.; Lee, P.D. Microscale simulation of stray grain formation in investment cast turbine blades. Mater. Sci. Eng. A 2004, 386, 129-139. [CrossRef]

10. Auburtin, P.B.L. Determination of the Influence of Growth Front Angle on Freckle Formation in Superalloys. Ph.D. Thesis, University of British Columbia, Vancouver, BC, Canada, 1998.

11. Auburtin, P.; Wang, T.; Cockcroft, S.L.; Mitchell, A. Freckle formation and freckle criterion in superalloy castings. Metall. Mater. Trans. B 2000, 31, 801-811. [CrossRef]

12. Fecht, H.-J.; Wunderlich, R.K.; Garandet, J.; Hayashi, M.; Mills, K.C.; Passerone, A.; Quested, P.N.; Ricci, E.; Schmidt-hohagen, F.; Seetharaman, S. Thermophysical properties of in738Lc, Mm247Lc and Cmsx-4 in the liquid and high temperature solid phase. Superalloys 2005, 467-476.

13. Harris, K.; Erickson, G.L.; Schwer, R.E. MAR M 247 derivations-CM 247 LC DS alloy CMSX single crystal alloys properties \& performance. In Superalloys 1984; The Minerals, Metals and Materials Society: Pittsburgh, PA, USA, 1904; pp. 221-230.

14. Huang, H.E.; Koo, C.H. Effect of zirconium on microstructure and mechanical properties of cast fine-grain CM 247 LC superalloy. Mater. Trans. 2004, 45, 554-561. [CrossRef]

15. Hong, J.; Ma, D.; Wang, J.; Wang, F.; Dong, A.; Sun, B.; Bührig-Polaczek, A. Geometrical effect of freckle formation on directionally solidified superalloy CM247 LC components. J. Alloys Compd. 2015, 648, 1076-1082. [CrossRef]

16. Hellawell, A.; Sarazin, J.R.; Steube, R.S. Channel convection in partly solidified systems. Philos. Trans. R. Soc. B Biol. Sci. 1993, 345, 507-544. [CrossRef]

17. Pollock, T.; Tin, S. Nickel-based superalloys for advanced turbine engines: Chemistry, microstructure and properties. J. Propuls. Power 2006, 22, 361-374. [CrossRef]

18. Brewster, G.; Dong, H.B.B.; Green, N.R.R.; D'Souza, N. Surface segregation during directional solidification of Ni-base superalloys. Metall. Mater. Trans. B 2008, 39, 87-93. [CrossRef]

19. Brewster, G.; D'Souza, N.; Ryder, K.S.; Simmonds, S.; Dong, H.B. Mechanism for formation of surface scale during directional solidification of Ni-base superalloys. Metall. Mater. Trans. A 2012, 43, 1288-1302. [CrossRef]

20. McDonald, R.J.; Hunt, J.D. Fluid motion through partially solid regions of a casting and its importance in understanding a type segregation. Trans. Metall. Soc. AIME 1969, 245, 1993-1997.

21. Valdés, J.; King, P.; Liu, X. On the formulation of a freckling criterion for Ni-based superalloy vacuum arc remelting ingots. Metall. Mater. Trans. A 2010, 41, 2408-2416. [CrossRef]

22. Yu, K.O.; Domingue, J.A.; Maurer, G.E.; Flanders, H.D. Macrosegregation in ESR and VAR processes. JOM 1986, 38, 46-50. [CrossRef]

23. Yu, K.O.; Domingue, J.A. Control of Solidification Structure in VAR and ESR Processed Alloy 718 Ingots. In Proceedings of the International Symposium on the Metallurgy and Applications of Superalloy 718, Pittsburgh, PA, USA, 12-14 June 1989.

24. Helms, A.D.; Adasczik, C.B.; Jackman, L.A. Extending the Size Limits of Cast/Wrought Superalloy Ingots. In Superalloys 1996; The Minerals, Metals \& Materials Society: Pittsburgh, PA, USA, 1996; pp. 427-433.

25. Yang, W.; Chang, K.-M.; Chen, W.; Mannan, S.; DeBarbadillo, J. Freckle criteria for the upward directional solidification of alloys. Metall. Mater. Trans. A 2001, 32, 397-406. [CrossRef]

26. Yang, W.H.; de Barbadillo, J.J.; Morita, K.; Suzuki, T.; Chen, W.; Chang, K.-M. A freckle criterion for the solidification of superalloys with a tilted solidification front. JOM 2004, 56, 56-61. [CrossRef]

27. Poirier, D.R. Permeability for flow of interdendritic liquid in columnar-dendritic alloys. Metall. Trans. B 1987, 18, 245-255. [CrossRef]

28. Bhat, M.S.; Poirier, D.R.; Heinrich, J.C. Permeability for cross flow through columnar-dendritic alloys. Metall. Mater. Trans. B 1995, 26, 1049-1056. [CrossRef]

29. Bhat, M.S.; Poirier, D.R.; Heinrich, J.C. A permeability length scale for cross flow through model structures. Energy 1995, 26, 1091-1092. [CrossRef]

(c) 2016 by the authors; licensee MDPI, Basel, Switzerland. This article is an open access article distributed under the terms and conditions of the Creative Commons Attribution (CC-BY) license (http:/ / creativecommons.org/licenses/by/4.0/). 